\title{
One-Step Hydrothermal Synthesis of a CoTe@rGO Electrode Material for Supercapacitors
}

\author{
Tianrui Wang ${ }^{1} \cdot$ Yupeng $\mathrm{Su}^{2} \cdot \mathrm{Mi} \mathrm{Xiao}^{2} \cdot \mathrm{Meilian}_{\mathrm{Zhao}}{ }^{2} \cdot$ Tingwu Zhao $^{2} \cdot$ Jianguo Shen $^{1}$
}

Received: 14 July 2021 / Revised: 7 August 2021 / Accepted: 3 September 2021 / Published online: 29 September 2021

(c) The Author(s) 2021

\begin{abstract}
CoTe@ reduced graphene oxide (CoTe@ @ rGO) electrode materials for supercapacitors were prepared by a one-step hydrothermal method in this paper. Compared with that of pure CoTe, the electrochemical performance of CoTe@ rGO was significantly improved. The results showed that the optimal CoTe@ rGO electrode material has a remarkably high specific capacitance of $810.6 \mathrm{~F} / \mathrm{g}$ at a current density of $1 \mathrm{~A} / \mathrm{g}$. At $5 \mathrm{~A} / \mathrm{g}$, the synthesized material retained $77.2 \%$ of its initial capacitance even after 5000 charge/discharge cycles, thereby demonstrating good cycling stability. Moreover, even at a high current density of $20 \mathrm{~A} / \mathrm{g}$, the composite electrode retained $79.0 \%$ of its specific capacitance at $1 \mathrm{~A} / \mathrm{g}$, thus confirming its excellent rate performance. An asymmetric supercapacitor (ASC) with a wider potential window and higher energy density was assembled by using $3 \mathrm{M} \mathrm{KOH}$ as the electrolyte, the CoTe@rGO electrode as the positive electrode, and active carbon as the negative electrode. The operating voltage of the supercapacitor could be increased to $1.6 \mathrm{~V}$, and its specific capacitance could reach $112.6 \mathrm{~F} / \mathrm{g}$ at $1 \mathrm{~A} / \mathrm{g}$. The specific capacitance retention rate of the fabricated supercapacitor after 5000 charge/discharge cycles at $5 \mathrm{~A} / \mathrm{g}$ was $87.1 \%$, which confirms its excellent cycling stability. In addition, the ASC revealed a high energy density of $40.04 \mathrm{~W} \cdot \mathrm{h} / \mathrm{kg}$ at a power density of $799.91 \mathrm{~W} / \mathrm{kg}$ and a high power density of $4004.93 \mathrm{~W} / \mathrm{kg}$ at an energy density of $33.43 \mathrm{~W} \cdot \mathrm{h} / \mathrm{kg}$. These results collectively show that CoTe@ $\mathrm{rGO}$ materials have broad application prospects.
\end{abstract}

Keywords Asymmetric supercapacitors $\cdot$ Cobalt telluride $\cdot$ Reduced graphene oxide $\cdot$ Electrode materials $\cdot$ High performance

\section{Introduction}

Continuous developments in the economy and society have led to the exhaustion of traditional non-renewable energy sources, including fossil fuels. The excessive use of nonrenewable energy sources has also caused the living environment of humans to deteriorate. Therefore, the development of new green energy sources, as well as new energy storage equipment, has become a major focus of research [1-4]. As a new type of energy storage device, supercapacitors can fill the gap between traditional capacitors and chemical batteries on account of its many advantages, which include high power density, high energy density, and long cycle life [5-8].

Mi Xiao

xiaomi@tju.edu.cn

1 School of Microelectronics, Tianjin University, Tianjin 300072, China

2 School of Electrical and Information Engineering, Tianjin University, Tianjin 300072, China
One of the most important methods to improve the performance of supercapacitors is to develop new types of electrode materials. Various transition metal chalcogenides composed of $\mathrm{Fe}, \mathrm{Co}, \mathrm{Ni}, \mathrm{S}, \mathrm{Se}$, and $\mathrm{Te}$, and their composites have become a key research direction on account of their excellent specific capacitance and variable valence state. In 2007, Tao et al. [9] obtained CoS electrode materials with a specific capacitance of $475 \mathrm{~F} / \mathrm{g}$ at a current density of $5 \mathrm{~mA} /$ $\mathrm{cm}^{2}$ via the hydrothermal reaction by using $\mathrm{NaS} \cdot 9 \mathrm{H}_{2} \mathrm{O}$ as a sulfur source and $\mathrm{Co}\left(\mathrm{CH}_{3} \mathrm{COO}\right)_{2} \cdot 4 \mathrm{H}_{2} \mathrm{O}$ as a cobalt source. In 2013, Yang et al. [10] successfully synthesized beta-NiS electrode materials with a specific capacitance of $857.76 \mathrm{~F} / \mathrm{g}$ at a current density of $2 \mathrm{~A} / \mathrm{g}$ via a solvothermal method. In 2013, Wang et al. [11]prepared CoSe nanotube-based electrode materials via a one-step hydrothermal method using $\mathrm{Co}\left(\mathrm{CO}_{3}\right)_{0.35} \mathrm{Cl}_{0.20}(\mathrm{OH})_{1.10}$ as the cobalt source and NaHSe as the selenium source; the authors obtained a specific capacitance of $238 \mathrm{~F} / \mathrm{g}$ at $1 \mathrm{~A} / \mathrm{g}$. In 2016, Guo et al. [12] applied successive cation exchange to obtain large-scale uniform $\mathrm{Ni}-\mathrm{Co}-\mathrm{Se}$ bimetallic ternary nanowires. An asymmetric 
supercapacitor (ASC) prepared with $\mathrm{Ni} @ \mathrm{Ni}_{0.8} \mathrm{Co}_{0.2} \mathrm{Se}$ and active carbon (AC) had a high specific capacitance of $86 \mathrm{~F} / \mathrm{g}$ at $1 \mathrm{~A} / \mathrm{g}$. In 2015, Chen et al. [13] prepared Ni-Co sulfides as electrode materials for supercapacitors; the resultant material, $\mathrm{Ni}_{1.5} \mathrm{Co}_{1.5} \mathrm{~S}_{4}$, was tested and found to have excellent performance with a maximum specific capacitance of 1093 $\mathrm{F} / \mathrm{g}$ at $1 \mathrm{~A} / \mathrm{g}$. Moreover, the energy density of an ASC with $\mathrm{Ni}_{1.5} \mathrm{Co}_{1.5} \mathrm{~S}_{4}$ as the anode material could reach $37.6 \mathrm{~W} \cdot \mathrm{h} / \mathrm{kg}$ at a power density of $775 \mathrm{~W} / \mathrm{kg}$, and a high power density of $2325 \mathrm{~W} / \mathrm{kg}$ could be achieved at an energy density of $17.7 \mathrm{~W} \cdot \mathrm{h} / \mathrm{kg}$. In 2017, Zhao et al. [14] prepared reduced graphene oxide ( $(\mathrm{GO}) / \mathrm{FeS}$ composite electrode materials on $\mathrm{Fe}$ foil via a facile one-pot hydrothermal method and obtained a specific capacitance of $300 \mathrm{~F} / \mathrm{g}$ and a maximum capacity retention rate of $97.5 \%$ after 2000 charge/discharge cycles. In 2018, Ye et al. [15] reported the preparation of Se-doped NiTe electrode materials for supercapacitors via a one-step hydrothermal method; the resulting electrode had a maximum specific capacitance of $998.2 \mathrm{~F} / \mathrm{g}$ at $1 \mathrm{~A} / \mathrm{g}$. In 2020, Xiao et al. [16] successfully prepared CoTe nanowires by the hydrothermal method and obtained a specific capacitance of $643.6 \mathrm{~F} / \mathrm{g}$ at $1 \mathrm{~A} / \mathrm{g}$.

These previous reports mainly demonstrated the potential applications of transition metal chalcogenides as supercapacitor electrode materials. However, research on the transition metal telluride is far from sufficient. Given the variable valence state of cobalt and the excellent metallicity of tellurium, compounds combining these two elements would theoretically have good electrochemical properties. The addition of graphene to the reactants is also believed to be able to improve the performance of the resultant electrode materials remarkably [17-22]. In 2019, Chu et al. [23] proposed a scalable method to achieve highly wettable graphene-polyaniline electrodes with a maximum specific capacitance of $225 \mathrm{~F} / \mathrm{g}$ at $1 \mathrm{~A} / \mathrm{g}$. In 2020, Zhang et al. [24] prepared $\mathrm{CoNi}_{2} \mathrm{~S}_{4} / \mathrm{rGO}$ composite electrode materials by a one-step pyrolysis method and obtained a maximum specific capacitance of $1526 \mathrm{~F} / \mathrm{g}$ at $2 \mathrm{~A} / \mathrm{g}$. This electrode material retained $93.7 \%$ of its original capacitance after 8000 charge/ discharge cycles at $3 \mathrm{~A} / \mathrm{g}$. In 2020, Shao et al. [25] prepared MXene/RGO composite aerogels with a fusiform shape. The specific capacitance of this material at $1 \mathrm{~A} / \mathrm{g}$ was $233 \mathrm{~F} / \mathrm{g}$. In 2021, Subhani et al. [26] used a graphene aerogel (GA) network impregnated on carbon fiber (CF) fabrics to prepare CF-reinforced composites. CF fabrics with $28 \%$ GA showed a specific capacitance of $92.5 \mathrm{~F} / \mathrm{g}$ at $1 \mathrm{mV} / \mathrm{s}$. Therefore, the objective of the present paper is to prepare electrode materials containing CoTe and rGO. The electric double-layer capacitance of the CoTe@rGO materials prepared in this work was provided by $\mathrm{rGO}$ and $\mathrm{CoTe}$, while the pseudocapacitance was provided by CoTe alone. Accurate experiments proved that all of the properties of CoTe@ $\mathrm{rGO}$ were greatly improved compared with those of pure CoTe.

\section{Experimental}

\section{Materials}

$\mathrm{Co}\left(\mathrm{NO}_{3}\right)_{2} \cdot 6 \mathrm{H}_{2} \mathrm{O}$ and $\mathrm{KOH}$ from Tianjin Kemiou Chemical Reagent Co., Ltd.; $\mathrm{Na}_{2} \mathrm{TeO}_{3}$, ethylene glycol, $\mathrm{N}_{2} \mathrm{H}_{4} \cdot \mathrm{H}_{2} \mathrm{O}(80$ wt \%), and $\mathrm{NH}_{3} \cdot \mathrm{H}_{2} \mathrm{O}$ from Shanghai Titan Scientific Co., Ltd.; graphene oxide (GO) from Suzhou Carbon Abundance Graphene Science and Technology Co., Ltd.; AC from Kuraray China Co., Ltd.; carbon cloth from Cetech Co., Ltd.; carbon black (super P) from Lion Corporation; and polytetrafluoroethylene (PTFE) aqueous solution (60 wt\%) from Daikin Fluorochemicals (China) Co., Ltd. were used as starting materials in this work. None of these chemicals were purified prior to their use.

\section{Synthesis of the CoTe@rGO Electrode Materials}

The CoTe@rGO electrode materials were prepared by a one-step hydrothermal method. First, $0.8 \mathrm{mmol}$ of $\mathrm{Co}\left(\mathrm{NO}_{3}\right)_{2} \cdot 6 \mathrm{H}_{2} \mathrm{O}, 0.8 \mathrm{mmol}$ of $\mathrm{Na}_{2} \mathrm{TeO}_{3}$, and different masses of $\mathrm{GO}(0,0.2,0.25,0.3$, and $0.35 \mathrm{mg})$ were added to $40 \mathrm{~mL}$ of ethylene glycol and magnetically stirred for $1 \mathrm{~h}$ to obtain a homogeneous solution. Then, $10 \mathrm{~mL}$ of $\mathrm{N}_{2} \mathrm{H}_{4} \cdot \mathrm{H}_{2} \mathrm{O}$ and $10 \mathrm{~mL}$ of $\mathrm{NH}_{3} \cdot \mathrm{H}_{2} \mathrm{O}$ were slowly added to the mixture as reductants. Stirring was performed for another $1 \mathrm{~h}$, during which the solution changed from purple to black. Next, the solution was transferred to a $100 \mathrm{~mL}$-capacity titanium alloy autoclave. The hermetic autoclave was heated in a muffle furnace at 150 ${ }^{\circ} \mathrm{C}$ for $12 \mathrm{~h}$. During the solvothermal reaction, CoTe was synthesized and GO was reduced. The resultant materials were named CoTe@rGO-0, CoTe@rGO-0.2, CoTe@rGO-0.25, CoTe@rGO-0.3, CoTe@ rGO-0.35, respectively, according to the amount of GO added to the CoTe mixture. The weight percentages of CoTe in the synthesized CoTe@ rGO composites were $100 \mathrm{wt} \%, 42.73 \mathrm{wt} \%, 37.38 \mathrm{wt} \%, 33.22 \mathrm{wt} \%$, and $29.89 \mathrm{wt} \%$, respectively. The obtained solid material was naturally cooled, rinsed several times with deionized water and alcohol with ultrasonication and centrifugation, and then dried for $12 \mathrm{~h}$ in a vacuum environment at $70{ }^{\circ} \mathrm{C}$. The final materials were prepared into working electrodes.

\section{Preparation of Working Electrode}

The working electrodes were prepared with 80 wt\% CoTe@ rGO as the active material, $10 \mathrm{wt} \%$ PTFE as an adhesive, and $10 \mathrm{wt} \%$ carbon black as a supporting material to improve the electrical conductivity of the electrode. These three materials were mixed in alcohol under ultrasound. The obtained mixtures were coated on clean carbon cloth $(1 \mathrm{~cm} \times 1 \mathrm{~cm})$ and dried in a vacuum at $60{ }^{\circ} \mathrm{C}$ for $12 \mathrm{~h}$ to 
obtain the working electrodes. The mass of all active materials coated on the electrode was $1 \mathrm{mg}$.

\section{Fabrication of the Asymmetric Supercapacitor}

An AC electrode was prepared as described in last Section. Briefly, AC, PTFE, and carbon black were ultrasonically mixed at a mass ratio of 8:1:1 in alcohol and coated on $1 \mathrm{~cm} \times 1 \mathrm{~cm}$ carbon cloth to obtain the AC electrode. The ASC was prepared by using the CoTe@rGO electrode as the positive electrode, the $\mathrm{AC}$ electrode as the negative electrode, and $3 \mathrm{M} \mathrm{KOH}$ as the electrolyte.

\section{Material Characterization}

The microstructures of the products were characterized by X-ray diffraction (XRD) with a Rigaku Ultima IV instrument at $40 \mathrm{kV}$ and $40 \mathrm{~mA}$. The scanning speed was $10 \% \mathrm{~min}$, and the $2 \theta$ range was $10^{\circ}-70^{\circ}$. The microstructural and chemical properties of the materials were characterized by field-emission scanning electron microscopy (FESEM) with a ZEISS MERLIN Compact microscope and energy dispersed X-ray spectroscopy (EDS), respectively.

\section{Electrochemical Measurements}

An electrochemical workstation (Model: CHI760E, Shanghai Chenghua) was used for all electrochemical measurements. The performance of three-electrode systems composed of the CoTe@rGO electrodes as the working electrode, $\mathrm{Hg} / \mathrm{HgO}$ as the reference electrode, platinum wire as the counter electrode was tested by cyclic voltammetry (CV), galvanostatic charge/discharge (GCD) analysis, and electrochemical impedance spectroscopy (EIS). The scanning rates of the $\mathrm{CV}$ tests ranged from $5 \mathrm{mV} / \mathrm{s}$ to $50 \mathrm{mV} / \mathrm{s}$, and the potential window was $0-0.6 \mathrm{~V}$. The voltage range of the GCD tests ranged from $0 \mathrm{~V}$ to $0.55 \mathrm{~V}$, and the current densities ranged from $1 \mathrm{~A} / \mathrm{g}$ to $20 \mathrm{~A} / \mathrm{g}$. The frequency range of the EIS tests ranged from $0.01 \mathrm{~Hz}$ to $100 \mathrm{kHz}$. The performance of the ASC, which is a two-electrode system, was evaluated on the same electrochemical workstation. Here, the scanning rates of the $\mathrm{CV}$ tests were changed from $5 \mathrm{mV} / \mathrm{s}$ to $100 \mathrm{mV} / \mathrm{s}$, the potential window was $0-1.6 \mathrm{~V}$, and the current densities of the GCD tests ranged from $1 \mathrm{~A} / \mathrm{g}$ to $5 \mathrm{~A} / \mathrm{g}$.

\section{Result and Discussion}

\section{Micromorphological and Structural Characterization of CoTe@rGO}

Figure 1 shows the XRD patterns of CoTe@rGO-0, CoTe@ rGO-0.2, CoTe@rGO-0.25, CoTe@rGO-0.3, and CoTe@

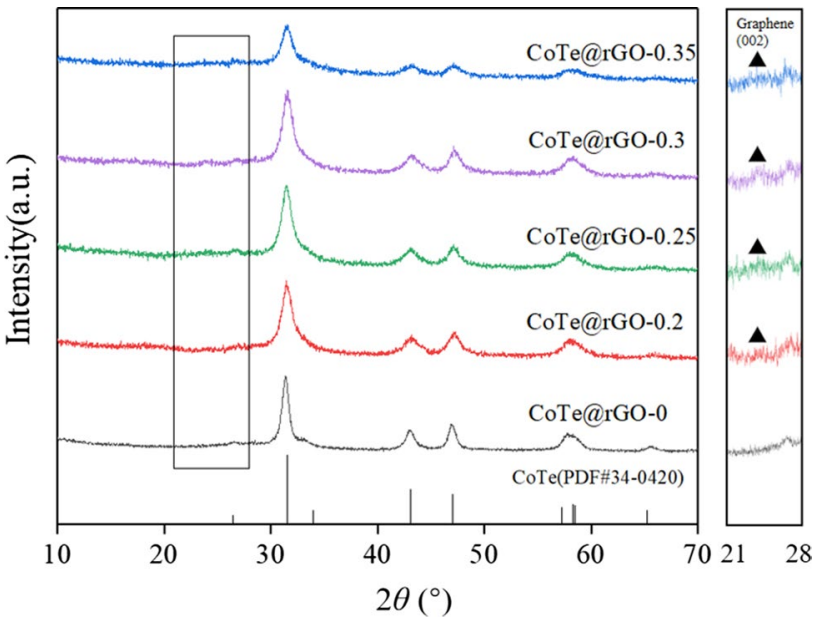

Fig. 1 X-ray diffraction patterns of CoTe@ rGO with different masses of reduced graphene oxide ( $\mathrm{rGO}$ )

rGO-0.35. The diffraction peaks of CoTe (PDF \#34-0420) at $31.34^{\circ}, 42.98^{\circ}, 46.88^{\circ}$, and $58.26^{\circ}$ were found in the spectra of all samples, thereby confirming the formation of CoTe. The diffraction peak of rGO could be observed at approximately $23^{\circ}$, and no GO diffraction peak was noted at $2 \theta=10.9^{\circ}$; these results indicate that GO was completely reduced to $\mathrm{rGO}$ during the preparation of the electrode materials $[27,28]$. The magnified diffraction intensities of peaks over the $2 \theta$ range of $21^{\circ}-28^{\circ}$ are displayed to the right of Fig. 1 to highlight the existence of rGO. Moreover, the diffraction peak intensities of CoTe@ $\mathrm{rGO}-0.35$ were lower than those of the three other samples, likely because excess rGO could inhibit the growth of CoTe.

FESEM images of CoTe@rGO-0, CoTe@rGO-0.2, CoTe@rGO-0.25, CoTe@rGO-0.3, and CoTe@rGO-0.35 are shown in Fig. 2. CoTe nanowires could be observed in all photos and appeared to grow on the rGO sheets (Fig. 2b-e). The amounts of CoTe nanowires in CoTe@ rGO-0.2 and CoTe@ rGO-0.25 indicated in Fig. 2b,c were greater than those in other samples; moreover, some nanowires did not grow on the rGO sheets and were stacked together instead. Compared with those of other samples, the nanowires of CoTe@ rGO-0.3 (Fig. 2d) demonstrated improved distribution and less agglomeration. The distribution of CoTe nanowires in CoTe@ $\mathrm{rGO}-0.35$ (Fig. 2e) was relatively loose, and their growth appeared to be restrained; these findings are likely due to the presence of excess rGO. These phenomena are consistent with the results shown in Fig. 1, that is, the diffraction peak intensities of CoTe@ $\mathrm{rGO}-0.35$ are weaker than those of the other samples. These findings confirm that excess rGO could degrade the pseudocapacitance of the resultant material. The introduction of rGO changed the micromorphology of the CoTe nanowires. 


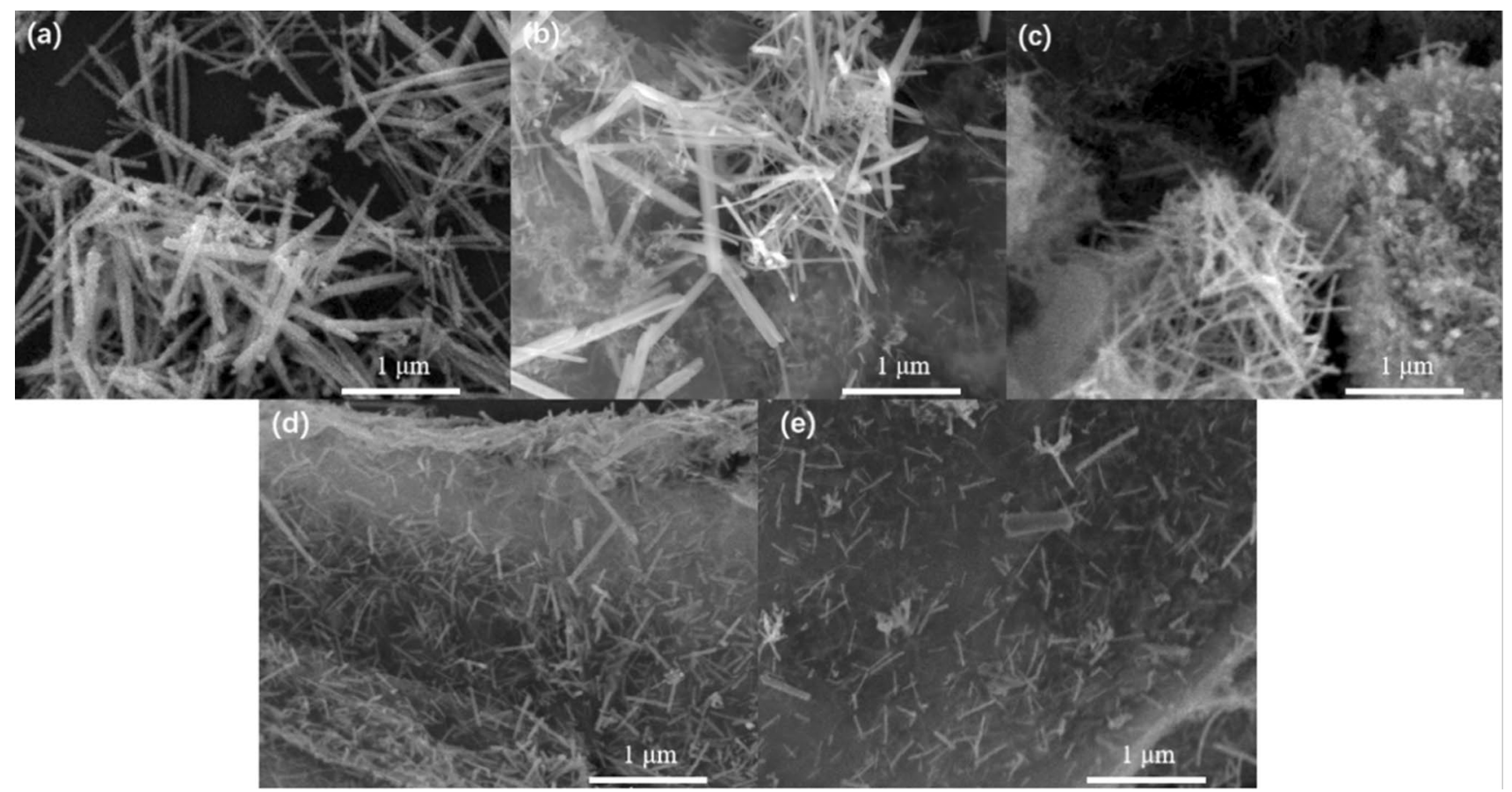

Fig. 2 Field-emission scanning electron microscopy images of a CoTe@rGO-0, b CoTe@ rGO-0.2, c CoTe@rGO-0.25, d CoTe@ rGO-0.3, and e CoTe@rGO-0.35

EDS-layered electron images of CoTe@ rGO-0.3 are provided in Fig. 3 to explore the distribution of different elements in the composites. Elemental $\mathrm{C}$ was mainly distributed in the lamellar layer, thus confirming that the lamellar material is rGO. Co and Te were mainly distributed in the nanowires. These findings, in combination with the XRD patterns obtained earlier, indicate that the CoTe nanowires are attached to the rGO layers. A large amount of aluminum could also be detected in the images due to the presence of aluminum in the test substrate.

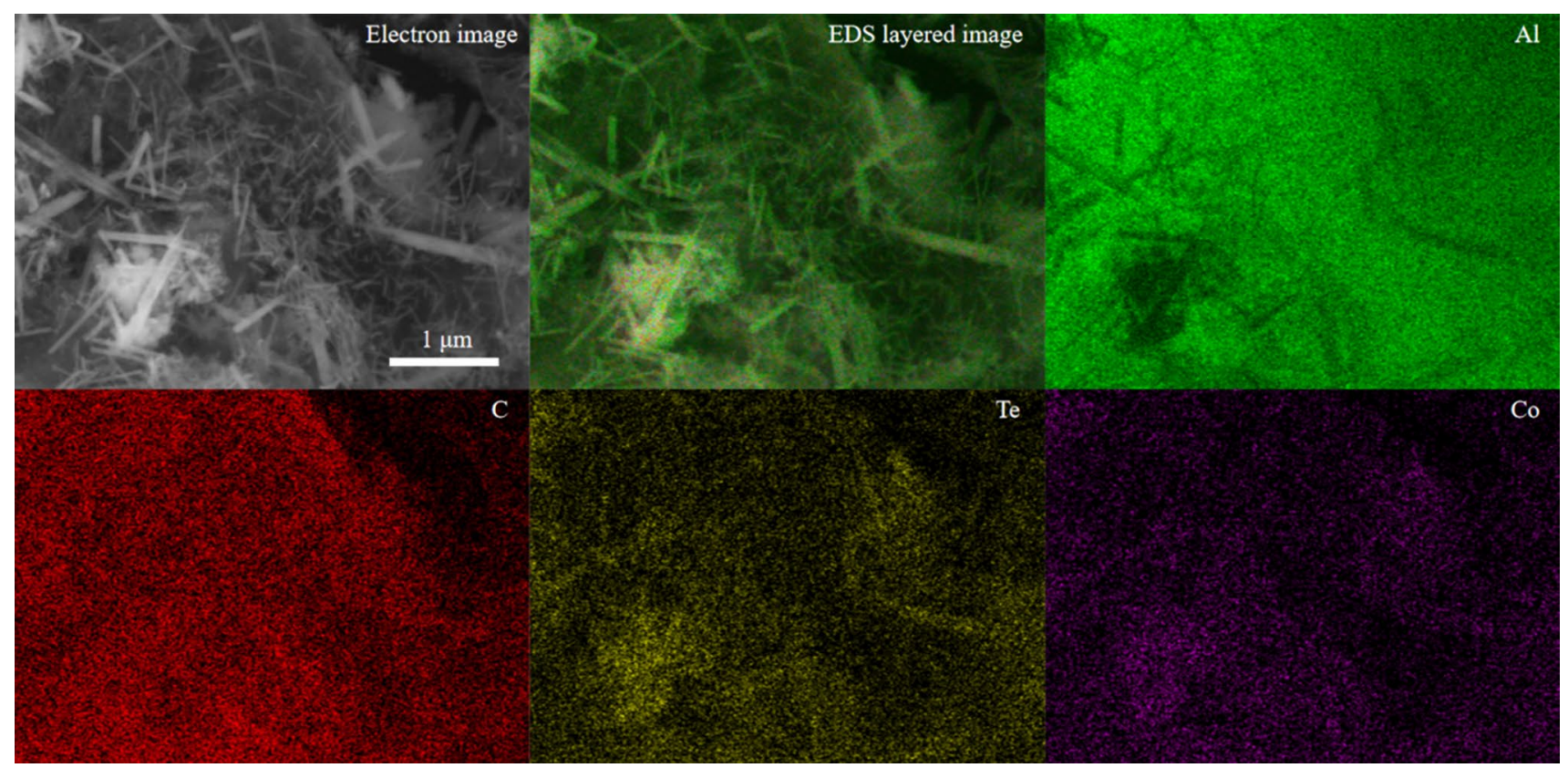

Fig. 3 Energy-dispersive X-ray spectroscopic layered electron images of CoTe@ rGO-0.3 


\section{Electrochemical Performance of CoTe@rG0}

Figure 4a shows the GCD curves of CoTe@ rGO with different masses of rGO at a current density of $1 \mathrm{~A} / \mathrm{g}$. The charge/ discharge time and specific capacitance of the CoTe@rGO materials increased with an increasing amount of rGO until CoTe@rGO-0.3. Further increases in the amount of rGO added to the electrode materials (i.e., CoTe@rGO-0.35) resulted in a decrease in specific capacitance compared with that of CoTe@rGO-0.3. Figure 4b clearly shows the variation of the specific capacitance of the electrode materials. The specific capacitances of CoTe@rGO-0, CoTe@ rGO-0.2, CoTe@rGO-0.25, CoTe@rGO-0.3, and CoTe@ rGO-0.35 at $1 \mathrm{~A} / \mathrm{g}$ were 643.6, 761.9, 786.3, 810.6, and $729.5 \mathrm{~F} / \mathrm{g}$, respectively. The specific capacitances of samples added with rGO improved compared with that of pure CoTe (CoTe@rGO-0), and the best electrochemical performance was observed in CoTe@rGO-0.3. The specific capacitance of $\mathrm{rGO}$ is approximately $100 \mathrm{~F} / \mathrm{g}$ at $1 \mathrm{~A} / \mathrm{g}$. The specific capacitance of CoTe@ rGO-0.3 was greater than the combined capacitances of CoTe@ rGO-0 and rGO, which indicates that the electrochemical performance of the materials could be effectively improved by the synergistic effects of CoTe nanowires and rGO [29]. These findings, in combination with the SEM results of the CoTe@ rGO composite materials, reveal that increases in $\mathrm{rGO}$ within a certain limit enhance the growth of CoTe nanowires by providing a suitably large surface area that could avoid the stacking and agglomeration of CoTe nanowires, thereby increasing their specific capacitance. However, excess rGO (e.g., CoTe@ rGO-0.35) could restrain the growth of CoTe by restricting mass transfer during the hydrothermal process, resulting in decreases in CoTe nanowire formation and pseudocapacitance. The results collectively indicate that the optimal mass of added GO is $0.3 \mathrm{mg}$; thus, all subsequent experiments were conducted using CoTe@rGO-0.3 as the electrode material.

Figure 5a shows the CV curves of the CoTe@ rGO-0.3 electrode obtained at different scan rates in $3 \mathrm{M} \mathrm{KOH}$. The shape of the curve and the presence of redox peaks indicate that the electrode is pseudocapacitive [30]. According to previous studies $[16,31]$, the curve shape is similar to that of pure CoTe nanowires, which means that the specific capacitance of the electrode may be mainly attributed to CoTe. The reaction occurring at the redox peaks can be expressed by the following equations [16, 31]:

$\mathrm{CoTe}+\mathrm{OH}^{-} \leftrightarrow \mathrm{CoTeOH}+\mathrm{e}^{-}$

$\mathrm{CoTeOH}+\mathrm{OH}^{-} \leftrightarrow \mathrm{CoTeO}+\mathrm{H}_{2} \mathrm{O}+\mathrm{e}^{-}$

The current density increased, and the redox peak of the electrode shifted with an increasing scan rate. However, the shape of the curve did not change remarkably, which indicates that the electrode has good rate performance. The GCD curves of the CoTe@ rGO-0.3 electrode at different current densities are shown in Fig. 5b. The symmetrical shape of the curves shown in this figure supports the reversible charge-discharge behavior of the electrode. The specific capacitance of the electrode could be calculated using the following formula [32]:

$C_{m}=\frac{I \times \Delta t}{m \times \Delta V}$

where $C_{m}(\mathrm{~F} / \mathrm{g})$ is the mass specific capacitance; $I(\mathrm{~A})$ and $\Delta t(\mathrm{~s})$ are the discharge current and time, respectively; $m(\mathrm{~g})$ is the mass of the active substance loaded onto the electrode;

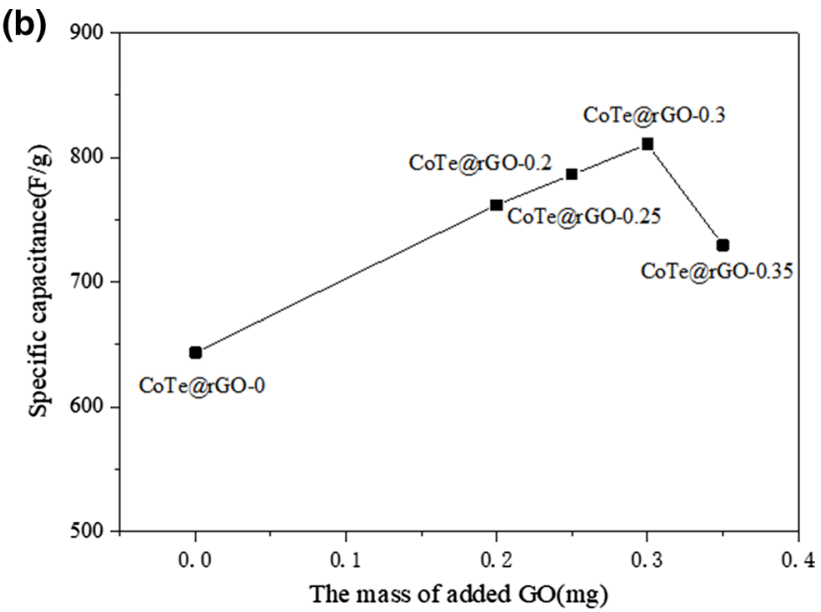

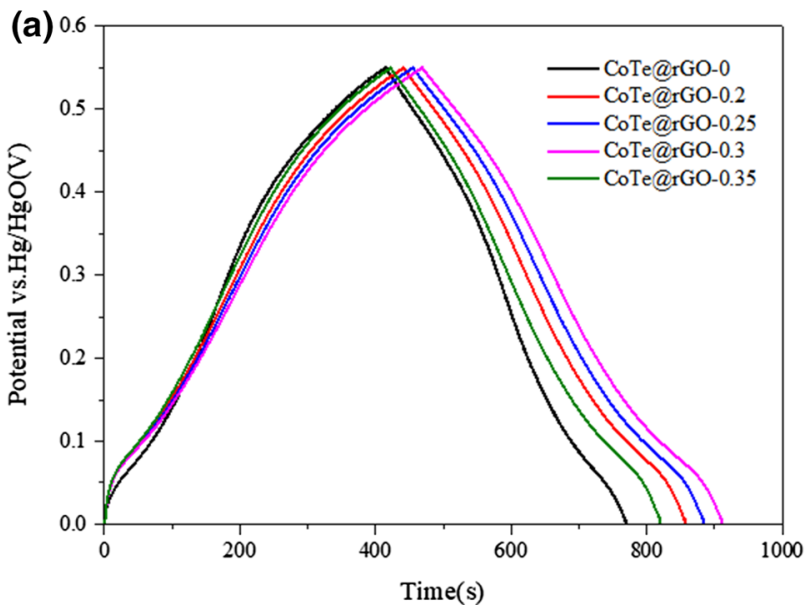

Fig. 4 Electrochemical properties of CoTe@rGO samples with different masses of reduced graphene oxide (rGO): a Galvanostatic charge/discharge curves and $\mathbf{b}$ specific capacitance curve 

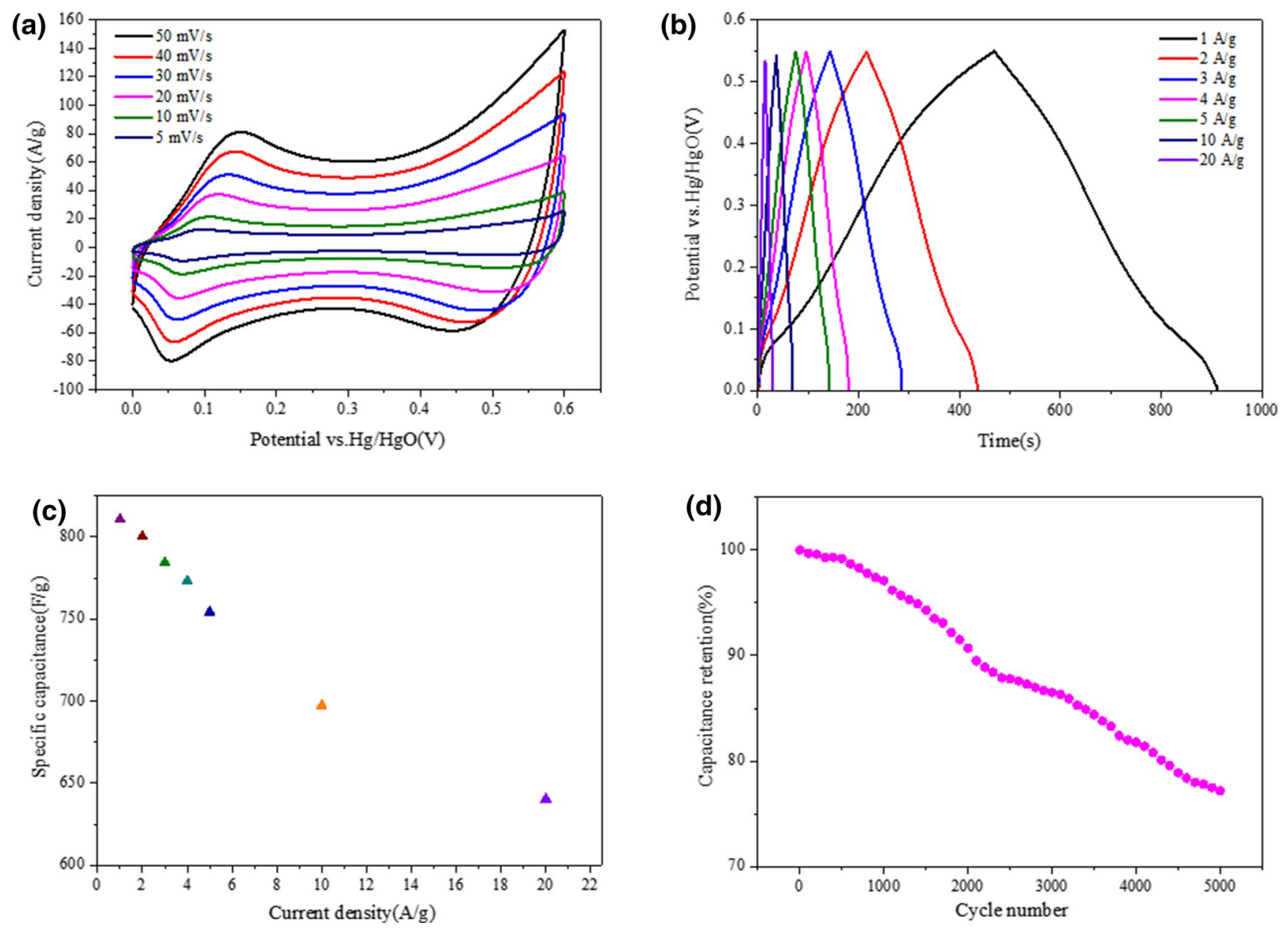

Fig. 5 a Cyclic voltammetry curve of the CoTe@rGO-0.3 electrode at different scan rates, $\mathbf{b}$ galvanostatic charge/discharge curve of the CoTe@rGO-0.3 electrode at different current densities, c changes in

the specific capacitance of the CoTe@rGO-0.3 electrode as a function of the current density, and $\mathbf{d}$ changes in the cycling stability of the CoTe@rGO-0.3 electrode as a function of the cycle number

and $\Delta V(\mathrm{~V})$ is the voltage window of the active substance. Calculations indicated that the $C_{m}$ of the CoTe@rGO-0.3 electrode at $1 \mathrm{~A} / \mathrm{g}$ is $810.6 \mathrm{~F} / \mathrm{g}$ and decreases with increasing current density, as shown in Fig. 5c. An increase in current density could lead to higher reaction rates, which may affect the entry of ions into the deeper layers of the electrode materials, resulting in a decrease in the utilization rate of the electrode and, ultimately, a decline in its energy storage performance [33]. Moreover, even at a high current density of $20 \mathrm{~A} / \mathrm{g}$, the composite electrode retained $79.0 \%$ of its specific capacitance at $1 \mathrm{~A} / \mathrm{g}$, thus confirming its excellent rate performance. Figure $5 \mathrm{~d}$ shows the cycling stability of the CoTe@ rGO-0.3 electrode at a high current density of 5 $\mathrm{A} / \mathrm{g}$ and 5000 charge/discharge cycles. As shown in Fig. 5d, the specific capacitance of the electrode initially declined slowly over the first 500 cycles and then began to decline at a faster rate because of the destruction of the microstructure of the material. The electrode retained approximately $77.2 \%$ of its initial specific capacitance after 5000 charge/

discharge cycles, which means it has good cycling stability. The comparative advantages of CoTe@ rGO over other CoTe materials are detailed in Table 1, which lists various performance indicators of previously reported CoTe materials for supercapacitors, including specific capacitance, cycling stability, and surface mass loading. Table 1 reveals that the specific capacitance of the sample prepared in this work is greater than those of all previously reported CoTe materials. This finding could be mainly attributed to the introduction of rGO, which enhances the microscale effects of the CoTe nanowires. After cycling 5000 times at a high current density of $5 \mathrm{~A} / \mathrm{g}$, the specific capacitance of the electrode remained fairly stable, thus confirming its advantageous properties.

Figure 6 shows the Nyquist diagrams of the CoTe@ rGO-0.3 electrode obtained before and after 5000 charge/ discharge cycles at $5 \mathrm{~A} / \mathrm{g}$ over the frequency range of $10^{-2}-10^{5} \mathrm{~Hz}$. The intercepts between the curve and $Z^{\prime}$-axis represent the internal resistance $\left(R_{\mathrm{s}}\right)$ of the system, which 
Table 1 Comparison of the specific capacitance, cycling stability, and surface mass loading of CoTe materials reported in previous and present studies

\begin{tabular}{lllll}
\hline Materials & Specific capacitance at 1A/g & Cyclic stability & Surface mass loading & References \\
\hline CoTe on CFP & $622.8 \mathrm{~F} / \mathrm{g}$ & $85 \%$ after 2000 cycle at $1 \mathrm{~A} / \mathrm{g}$ & $1.2 \mathrm{mg} / \mathrm{cm}^{2}$ & {$[31]$} \\
CoTe nanowires & $643.6 \mathrm{~F} / \mathrm{g}$ & $76.9 \%$ after 5000 cycle at $5 \mathrm{~A} / \mathrm{g}$ & $1.1 \mathrm{mg} / \mathrm{cm}^{2}$ & {$[16]$} \\
CoTe nanorods & $148 \mathrm{C} / \mathrm{g}$ at $0.5 \mathrm{~V}(296 \mathrm{~F} / \mathrm{g})$ & $99 \%$ after 5000 cycle at $10 \mathrm{~A} / \mathrm{g}$ & $1 \mathrm{mg} / \mathrm{cm}^{2}$ & {$[34]$} \\
CoTe@C on nickel foam & $1038 \mathrm{mF} / \mathrm{cm}^{2}$ with $2 \mathrm{mg}$ active & $87.5 \%$ after 10,000 cycle at $1 \mathrm{~mA} /$ & $2 \mathrm{mg} / \mathrm{cm}^{2}$ & {$[35]$} \\
& material $(519 \mathrm{~F} / \mathrm{g})$ & $\mathrm{cm}^{2}(0.5 \mathrm{~A} / \mathrm{g})$ & & \\
CoTe@ rGO & $810.6 \mathrm{~F} / \mathrm{g}$ & $77.2 \%$ after 5000 cycle at $5 \mathrm{~A} / \mathrm{g}$ & $1 \mathrm{mg} / \mathrm{cm}^{2}$ & This work \\
\hline
\end{tabular}

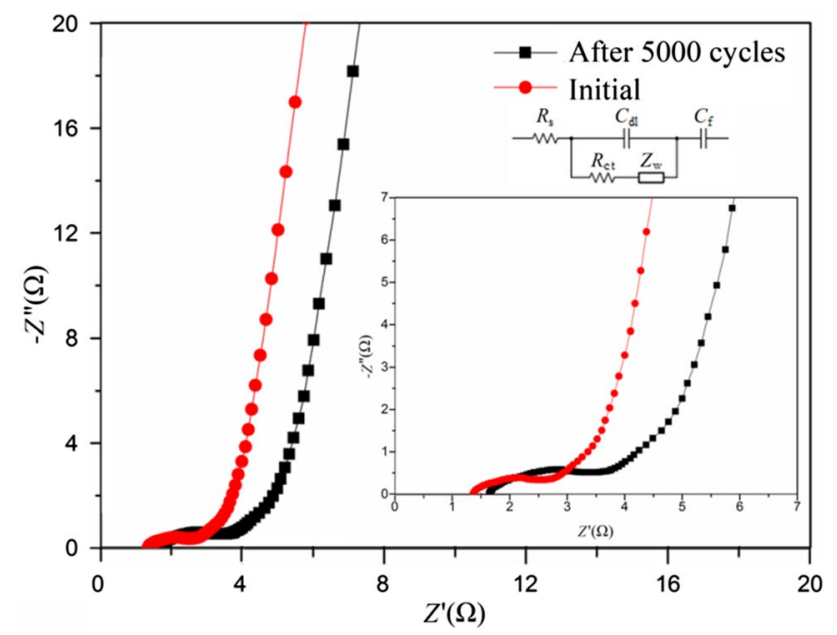

Fig. 6 Nyquist diagrams of the CoTe@rGO-0.3 electrode before and after 5000 charge/discharge cycles with an equivalent circuit

includes the internal resistance of the electrolyte and electrode materials. The semicircles near the origin of the coordinates represent the Faradaic charge-transfer resistance $\left(R_{\mathrm{ct}}\right)$, and the straight lines extending outward from the semicircles represent the Warburg impedance [36]. Prior to charge/discharge cycling, $R_{\mathrm{s}}$ and $R_{\mathrm{ct}}$ of the electrode were 1.367 and $0.947 \Omega$, respectively. After 5000 charge/discharge cycles, $R_{\mathrm{s}}$ and $R_{\mathrm{ct}}$ increased to 1.647 and $1.469 \Omega$, respectively. This finding demonstrates good recombination between the CoTe nanowires and rGO. The observed increase in resistance may be attributed to the irreversible damage to the microstructure of the materials caused by multiple redox reactions. The angles between the straight lines and the $Z$ '-axis were fairly large before and after cycling, which means the electrode material has abundant ion diffusion paths and low interfacial charge-transfer resistance between the electrode and electrolyte [37].

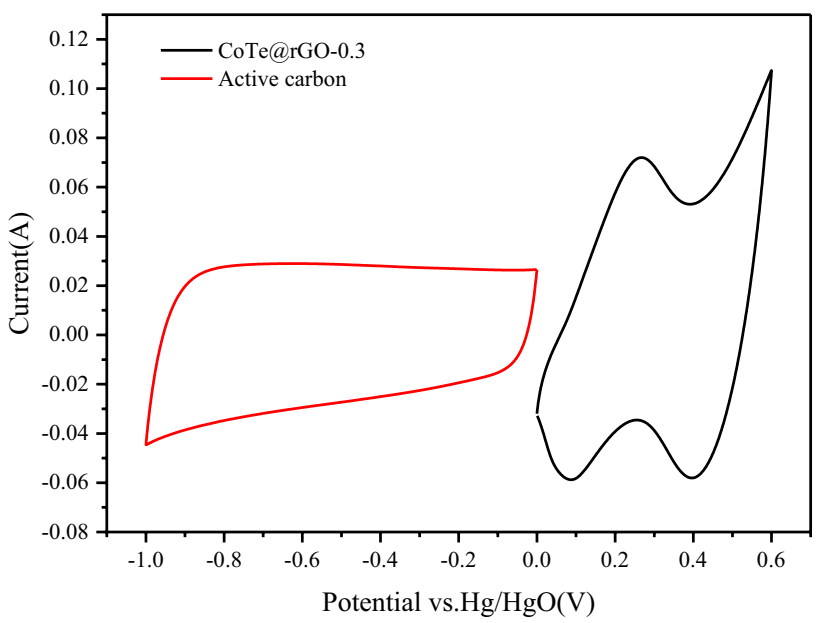

Fig. 7 Cyclic voltammetry curves of CoTe@ rGO-0.3 and active carbon electrodes in a three-electrode system at a scan rate of $50 \mathrm{mV} / \mathrm{s}$

\section{Electrochemical Performance of the Asymmetrical Supercapacitor}

An ASC was successfully prepared using the CoTe@rGO0.3 electrode as the positive electrode, an AC electrode as the negative electrode, and $3 \mathrm{M} \mathrm{KOH}$ as the electrolyte. Figure 7 shows the CV curves of the CoTe@rGO-0.3 and AC electrodes in a three-electrode system at a scanning rate of $50 \mathrm{mV} / \mathrm{s}$. The potential windows of the AC and CoTe@ rGO- 0.3 electrodes ranged from $-1.0 \mathrm{~V}$ to $0 \mathrm{~V}$ and from $0 \mathrm{~V}$ to $0.6 \mathrm{~V}$, respectively. The potential window of the ASC, which is composed of these two electrodes, could theoretically be expanded to $1.6 \mathrm{~V}$. However, prior to the fabrication of the ASC, the masses of the positive and negative electrodes must be balanced to ensure that the electrochemical reaction occurs equally on both electrodes and improve the performance of the ASC. The specific calculation method is as follows $[38,39]$ :

$q=C_{m} \times \Delta V \times m$ 
$q^{+}=q^{-}$

$\frac{m^{+}}{m^{-}}=\frac{C_{m^{-}} \times \Delta V^{-}}{C_{m^{+}} \times \Delta V^{+}}$

where $q$ is the charge stored in the electrode. At $1 \mathrm{~A} / \mathrm{g}$, the specific capacitances of the CoTe@rGO-0.3 and AC electrodes were 810.6 and $257.4 \mathrm{~F} / \mathrm{g}$, respectively. Therefore, under the premise that the active substance load of the CoTe@ $\mathrm{rGO}-0.3$ composite electrode is $1 \mathrm{mg}$, the active substance load of the AC electrode should be $1.89 \mathrm{mg}$.

Figure 8 illustrates the CV and GCD curves of the ASC. Figure $8 \mathrm{a}$ shows the $\mathrm{CV}$ curves of the ASC at different potential windows ranging from $0.8 \mathrm{~V}$ to $1.6 \mathrm{~V}$ at a scan rate of $100 \mathrm{mV} / \mathrm{s}$. Redox peaks gradually appeared as the potential window increased. The shape of the $\mathrm{CV}$ curve remained symmetric and stable when the maximum potential window was reached, thus indicating that the ASC potential window could reach the theoretical maximum value. Figure $8 \mathrm{~b}$ shows the GCD curves of the ASC at different potential windows ranging from $0.8 \mathrm{~V}$ to $1.6 \mathrm{~V}$ at $1 \mathrm{~A} / \mathrm{g}$. The shapes of the GCD curves obtained were virtually identical and highly symmetrical with increasing potential windows. This finding confirms that the ASC can perform well at a potential window ranging from $0 \mathrm{~V}$ to $1.6 \mathrm{~V}$ [40].

Figure 9a shows the CV curve of the ASC at different scan rates ranging from $5 \mathrm{mV} / \mathrm{s}$ to $100 \mathrm{mV} / \mathrm{s}$, and a redox peak could clearly be seen. The shapes of the CV curves were maintained despite increases in scan rate. Figure $9 b$ shows the GCD curves of the ASC at different current densities ranging from $1 \mathrm{~A} / \mathrm{g}$ to $5 \mathrm{~A} / \mathrm{g}$. The curves in the figure demonstrated the excellent reversibility of the ASC, which had a specific capacitance of $112.6 \mathrm{~F} / \mathrm{g}$ at $1 \mathrm{~A} / \mathrm{g}$.
As the current density increases, the ions in the electrolyte become more difficult to bind to the electrode material, thereby resulting in a decrease in specific capacitance. Although the specific capacitance of the ASC decreased with increasing current density, $83.4 \%$ of the specific capacitance obtained at $1 \mathrm{~A} / \mathrm{g}$ was preserved even at a high current density of $5 \mathrm{~A} / \mathrm{g}$, as shown in Fig. 9c. After 5000 charge/ discharge cycles at a current density of $5 \mathrm{~A} / \mathrm{g}$ (Fig. 9d), the specific capacitance of the ASC was still greater than $87.1 \%$ of the original value, revealing the excellent cycling stability of this system.

The Ragone plot in Fig. 10 shows the relationship between the energy densities and power densities of CoTe@ rGO-0.3॥AC ASC. The energy and power densities of the ASC were calculated as follows [31, 41]:

$E=\frac{C_{m}(\Delta V)^{2}}{2}$

$P=\frac{E \times 3600}{\Delta t}$

where $E(\mathrm{Wh} / \mathrm{kg})$ is the energy density; $P(\mathrm{~W} / \mathrm{kg})$ is the power density. The ASC revealed a high energy density of $40.04 \mathrm{~W} \cdot \mathrm{h} / \mathrm{kg}$ at a power density of $799.91 \mathrm{~W} / \mathrm{kg}$ and a high power density of $4004.93 \mathrm{~W} / \mathrm{kg}$ at an energy density of $33.43 \mathrm{~W} \cdot \mathrm{h} / \mathrm{kg}$. These results are better than those obtained from pure CoTe nanowiresllAC ASCs reported in Refs. [16, 31]. The findings confirm that the energy storage performance of CoTe@rGO is greatly improved compared with that of CoTe nanowires, thus, the synthesized material is a potential electrode material for supercapacitors.
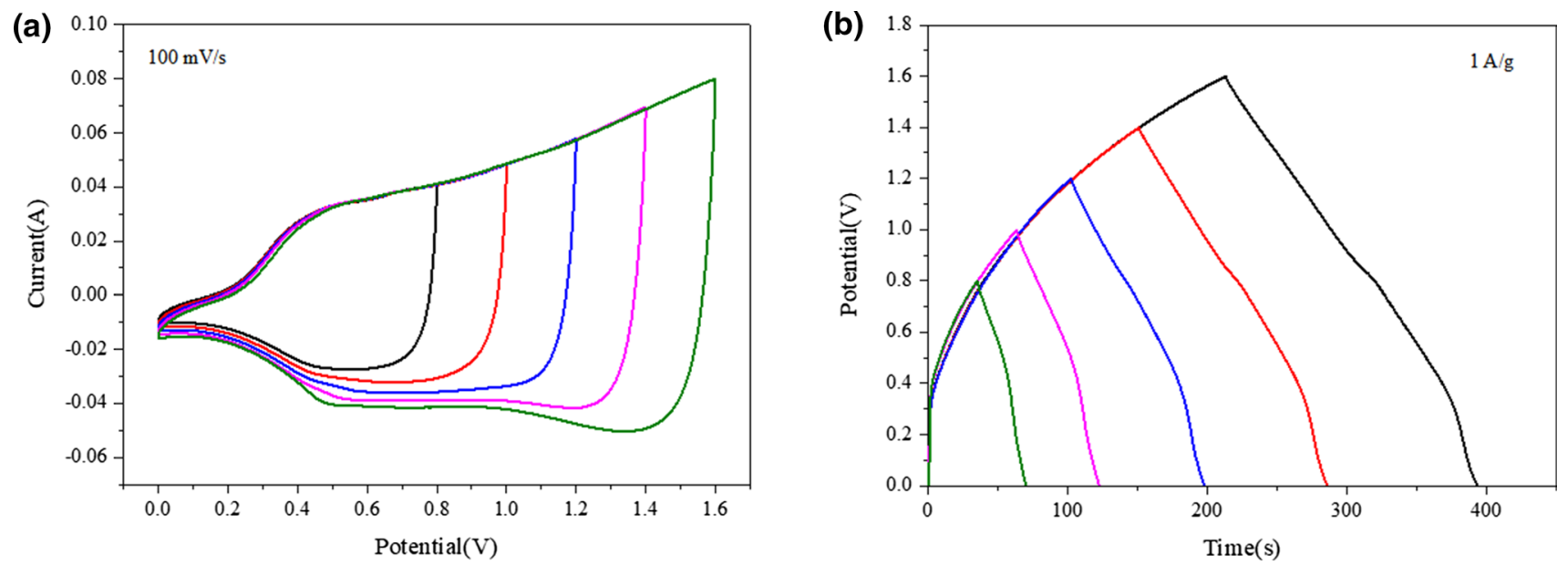

Fig. 8 a Cyclic voltammetry curves of the asymmetric supercapacitor (ASC) at different potential windows under a scan rate of $100 \mathrm{mV} / \mathrm{s}$. b Galvanostatic charge/discharge curves of the ASC at different potential windows at $1 \mathrm{~A} / \mathrm{g}$ 

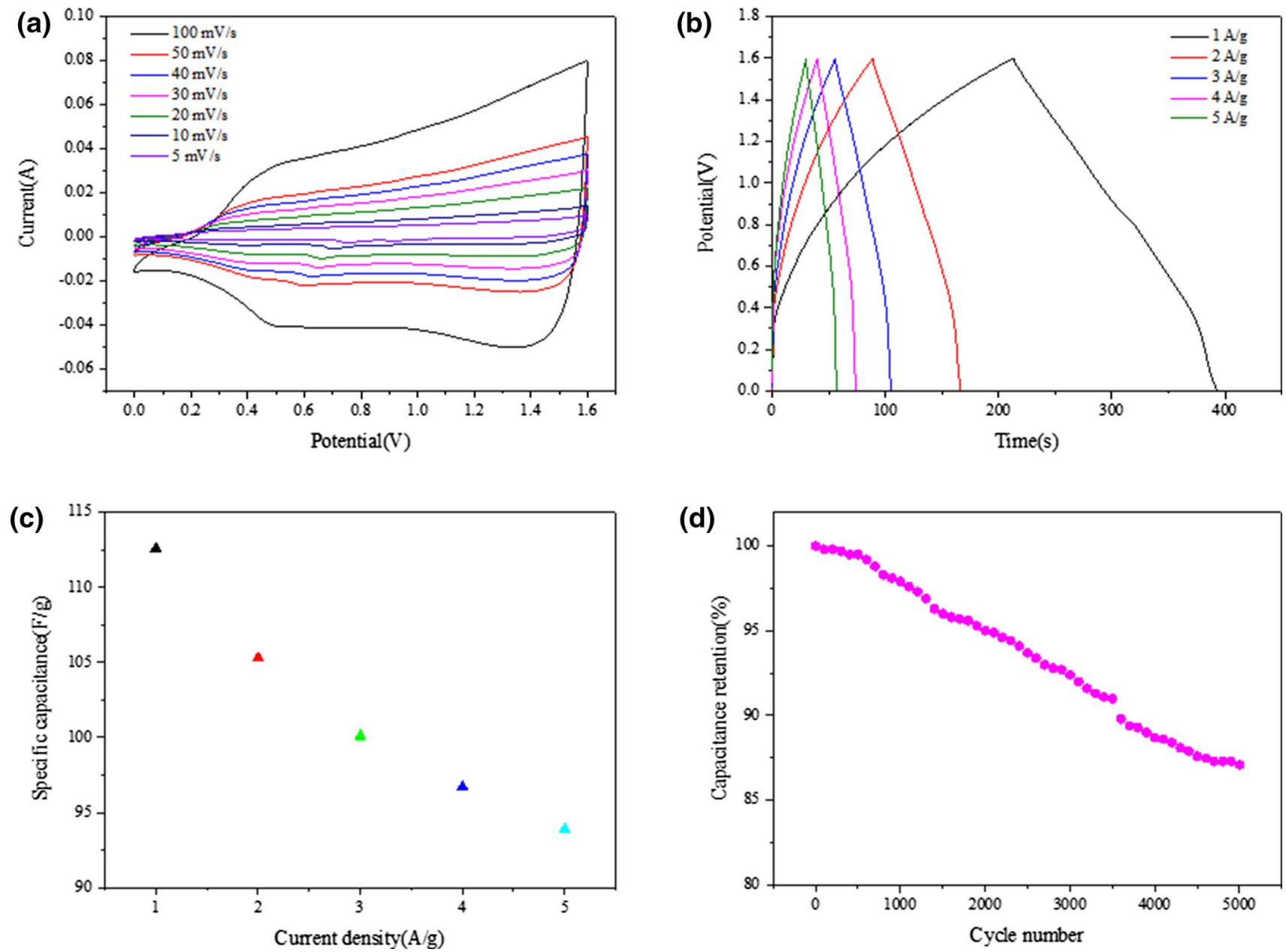

Fig. 9 a Cyclic voltammetry curves of the asymmetrical supercapacitor (ASC) at different scan rates, $\mathbf{b}$ galvanostatic charge/discharge curves of the ASC at different current densities, $\mathbf{c}$ changes in the

(d)

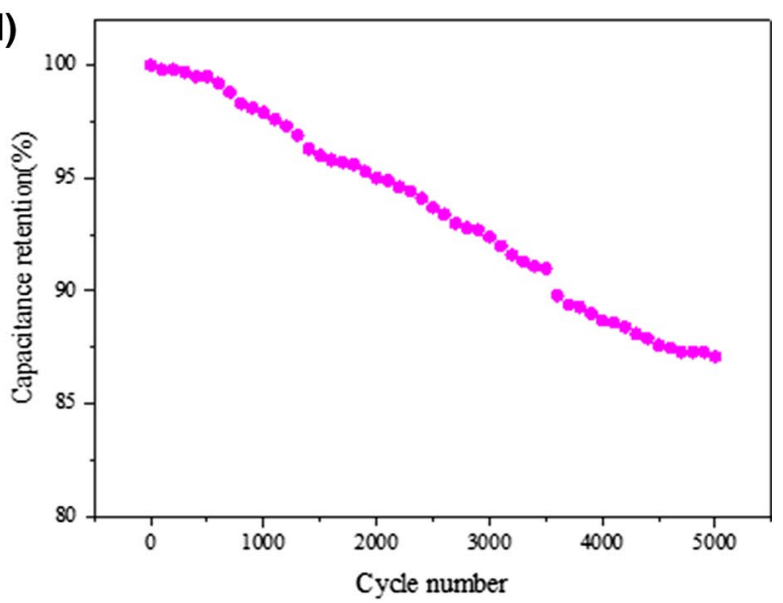

specific capacitance of the ASC as a function of the current density, and $\mathbf{d}$ changes in the cycling stability of the ASC as a function of the cycle number

\section{Conclusion}

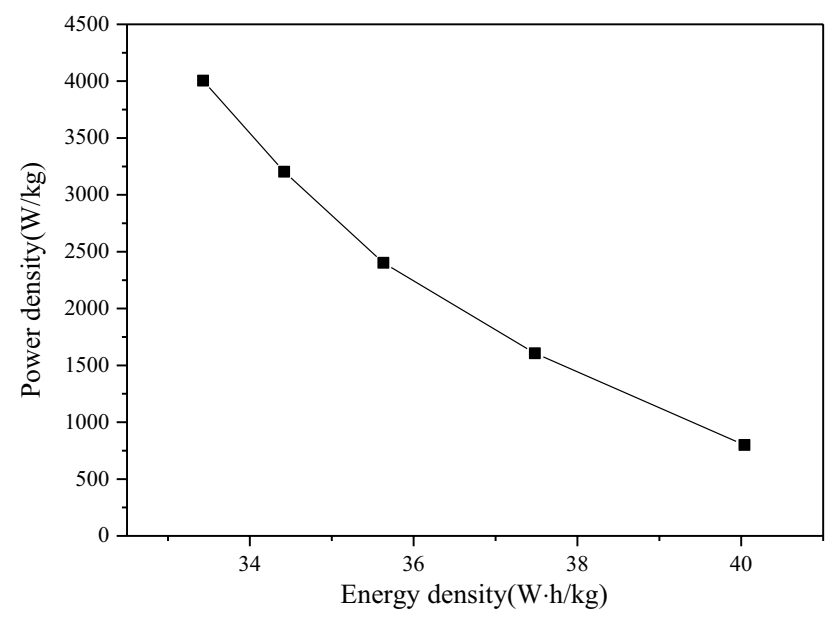

Fig. 10 Ragone plot of the CoTe@ rGO-0.3\|AC asymmetric supercapacitor

CoTe@ rGO composite materials were successfully synthesized by adding $\mathrm{GO}$ to the reaction materials. The addition of $0.3 \mathrm{mg}$ GO to $0.8 \mathrm{mmol}$ of $\mathrm{Co}\left(\mathrm{NO}_{3}\right)_{2} \cdot 6 \mathrm{H}_{2} \mathrm{O}$ and $0.8 \mathrm{mmol}$ $\mathrm{Na}_{2} \mathrm{TeO}_{3}$ yielded a composite material with a highly uniform distribution and optimal electrochemical performance. The specific capacitance of the electrode prepared with CoTe@ rGO could reach $810.6 \mathrm{~F} / \mathrm{g}$ at $1 \mathrm{~A} / \mathrm{g}$; such capacitance is much higher than that of pure CoTe nanowires. At the current density of $20 \mathrm{~A} / \mathrm{g}$, the composite electrode retained $79.0 \%$ of its specific capacitance at $1 \mathrm{~A} / \mathrm{g}$, indicating the excellent rate performance. An ASC in which the CoTe@ rGO composite material and $\mathrm{AC}$ were used as electrodes was fabricated, and the specific capacitance of this system was $112.6 \mathrm{~F} / \mathrm{g}$ at $1 \mathrm{~A} / \mathrm{g}$. After 5000 charge/discharge cycles at a current density of $5 \mathrm{~A} / \mathrm{g}$, the specific capacitance of the ASC remained as high as $87.1 \%$, indicating the excellent cycling stability. The maximum energy density of the ASC 
was $40.04 \mathrm{~W} \cdot \mathrm{h} / \mathrm{kg}$, and its power density was as high as $4004.93 \mathrm{~W} / \mathrm{kg}$ at an energy density of $33.43 \mathrm{~W} \cdot \mathrm{h} / \mathrm{kg}$. These results collectively confirm that the preparation of CoTe@ rGO is an effective means to improve the properties of CoTe electrode materials. The electrode materials prepared in this work demonstrate broad application prospects.

Acknowledgements This work was supported by the National Natural Science Foundation of China (No. 51877146).

\section{Declarations}

Conflict of interest The authors declare that there is no conflict of interest.

Open Access This article is licensed under a Creative Commons Attribution 4.0 International License, which permits use, sharing, adaptation, distribution and reproduction in any medium or format, as long as you give appropriate credit to the original author(s) and the source, provide a link to the Creative Commons licence, and indicate if changes were made. The images or other third party material in this article are included in the article's Creative Commons licence, unless indicated otherwise in a credit line to the material. If material is not included in the article's Creative Commons licence and your intended use is not permitted by statutory regulation or exceeds the permitted use, you will need to obtain permission directly from the copyright holder. To view a copy of this licence, visit http://creativecommons.org/licenses/by/4.0/.

\section{References}

1. Aricò AS, Bruce P, Scrosati B et al (2005) Nanostructured materials for advanced energy conversion and storage devices. Nat Mater 4(5):366-377 https://www.ncbi.nlm.nih.gov/pubmed/15867920/

2. Hall PJ, Bain EJ (2008) Energy-storage technologies and electricity generation. Energy Pol. 36(12):4352-4355. https://doi.org/10. 1016/j.enpol.2008.09.037

3. Zhang J, Zhao XS (2012) On the configuration of supercapacitors for maximizing electrochemical performance. ChemSusChem 5(5):818-841 https://www.ncbi.nlm.nih.gov/pubmed/22550045/

4. Wang GP, Zhang L, Zhang JJ (2012) A review of electrode materials for electrochemical supercapacitors. Chem Soc Rev 41(2):797-828 https://www.ncbi.nlm.nih.gov/pubmed/21779609/

5. Simon P, Gogotsi Y (2008) Materials for electrochemical capacitors. Nat Mater 7(11):845-854 https://www.ncbi.nlm.nih.gov/ pubmed/18956000/

6. Miller JR, Simon P (2008) Materials science: electrochemical capacitors for energy management. Science 321(5889):651-652 https://www.ncbi.nlm.nih.gov/pubmed/18669852/

7. Zhang G, David Lou XW (2013) Controlled growth of $\mathrm{NiCo}_{2} \mathrm{O}_{4}$ nanorods and ultrathin nanosheets on carbon nanofibers for highperformance supercapacitors. Sci Rep 3:1470 https://www.ncbi. nlm.nih.gov/pmc/articles/PMC3600593/

8. Wang Y, Song Y, Xia Y (2016) Electrochemical capacitors: mechanism, materials, systems, characterization and applications. Chem Soc Rev 45(21):5925-5950 https://www.ncbi.nlm.nih.gov/ pubmed/27545205/

9. Tao F, Zhao YQ, Zhang GQ et al (2007) Electrochemical characterization on cobalt sulfide for electrochemical supercapacitors. Electrochem Commun 9(6):1282-1287. https://doi.org/10.1016/j. elecom.2006.11.022
10. Yang JQ, Duan XC, Qin Q et al (2013) Solvothermal synthesis of hierarchical flower-like $\beta$-NiS with excellent electrochemical performance for supercapacitors. J Mater Chem A 1(27):7880-7884. https://doi.org/10.1039/C3TA11167A

11. Wang ZH, Sha Q, Zhang FW et al (2013) Synthesis of poly crystalline cobalt selenide nanotubes and their catalytic and capacitive behaviors. CrystEngComm 15(29):5928. https://doi.org/10.1039/ c3ce40152a

12. Guo KL, Cui SZ, Hou HW et al (2016) Hierarchical ternary NiCo-Se nanowires for high-performance supercapacitor device design. Dalton Trans 45(48):19458-19465 https://www.ncbi.nlm. nih.gov/pubmed/27885371/

13. Chen HC, Jiang JJ, Zhao YD et al (2015) One-pot synthesis of porous nickel cobalt sulphides: tuning the composition for superior pseudocapacitance. J Mater Chem A 3(1):428-437. https:// doi.org/10.1039/c4ta04420g

14. Zhao CJ, Shao XX, Zhu ZQ et al (2017) One-pot hydrothermal synthesis of RGO/FeS composite on Fe foil for high performance supercapacitors. Electrochim Acta 246:497-506. https://doi.org/ 10.1016/j.electacta.2017.06.090

15. Ye BR, Huang ML, Jiang S et al (2018) In-situ growth of Sedoped NiTe on nickel foam as positive electrode material for high-performance asymmetric supercapacitor. Mater Chem Phys 211:389-398. https://doi.org/10.1016/j.matchemphys.2018.03.011

16. Xiao M, Su YP, Zhao ML et al (2020) Synthesis of CoTe nanowires: a new electrode material for supercapacitor with high stability and high performance. Nanotechnology 31(5):055706https:// www.ncbi.nlm.nih.gov/pubmed/31614344/

17. Shi WH, Zhu JX, Sim DH et al (2011) Achieving high specific charge capacitances in $\mathrm{Fe}_{3} \mathrm{O}_{4}$ /reduced graphene oxide nanocomposites. J Mater Chem 21(10):3422. https://doi.org/10.1039/c0jm0 $3175 \mathrm{e}$

18. Ma H, He J, Xiong DB et al (2016) Nickel cobalt hydroxide @ Reduced graphene oxide hybrid nanolayers for high performance asymmetric supercapacitors with remarkable cycling stability. ACS Appl Mater Interfaces 8(3):1992-2000 https://www.ncbi. nlm.nih.gov/pubmed/26742692/

19. Zhao CJ, Shao XX, Zhang YX et al (2016) $\mathrm{Fe}_{2} \mathrm{O}_{3}$ /reduced graphene oxide $/ \mathrm{Fe}_{3} \mathrm{O}_{4}$ composite in situ grown on $\mathrm{Fe}$ foil for high-performance supercapacitors. ACS Appl Mater Interfaces 8(44):30133-30142 https://www.ncbi.nlm.nih.gov/pubmed/27759 $364 /$

20. Abdel-Aal SK, Attia SY, Mohamed SG (2019) Facile synthesis of $\mathrm{Mn}_{3} \mathrm{O}_{4}$-rGO nanocomposite as an efficient electrode material for application in supercapacitors. J Electron Mater 48(8):4977-4986. https://doi.org/10.1007/s11664-019-07305-4

21. BoopathiRaja R, Parthibavarman M, Prabhu S et al (2020) A facile one step hydrothermal induced hexagonal shaped $\mathrm{CuS} / \mathrm{rGO}$ nanocomposites for asymmetric supercapacitors. Mater Today: Proc 26:3507-3513. https://doi.org/10.1016/j.matpr.2019.06.006

22. Ghosh S, Samanta P, Samanta P et al (2020) Investigation of electrochemical charge storage efficiency of $\mathrm{NiCo}_{2} \mathrm{Se}_{4} / \mathrm{RGO}$ composites derived at varied duration and its asymmetric supercapacitor device. Energy Fuels 34(10):13056-13066. https://doi.org/10. 1021/acs.energyfuels.0c02152

23. Chu XY, Huang TQ, Hu YQ et al (2020) Wet-spinning assembly of nitrogen-doped graphene film for stable graphene-polyaniline supercapacitor electrodes with high mass loading. Sci China Mater 63(10):1889-1897. https://doi.org/10.1007/s40843-019-9436-1

24. Zhang KY, Wei YH, Huang J et al (2020) A generalized onestep in situ formation of metal sulfide/reduced graphene oxide nanosheets toward high-performance supercapacitors. Sci China Mater 63(10):1898-1909. https://doi.org/10.1007/ s40843-020-1371-y

25. Shao L, Xu JJ, Ma JZ et al (2020) MXene/RGO composite aerogels with light and high-strength for supercapacitor electrode 
materials. Compos Commun 19:108-113. https://doi.org/10. 1016/j.coco.2020.03.006

26. Subhani K, Jin X, Mahon PJ et al (2021) Graphene aerogel modified carbon fiber reinforced composite structural supercapacitors. Compos Commun 24:100663. https://doi.org/10.1016/j.coco. 2021.100663

27. AminuddinRosli NH, Lau KS, Winie T et al (2021) Microwaveassisted reduction of graphene oxide for an electrochemical supercapacitor: structural and capacitance behavior. Mater Chem Phys 262:124274. https://doi.org/10.1016/j.matchemphys.2021.124274

28. Zhao ZY, Shen T, Liu ZH et al (2020) Facile fabrication of binderfree reduced graphene oxide $/ \mathrm{MnO}_{2} / \mathrm{Ni}$ foam hybrid electrode for high-performance supercapacitors. J Alloy Compd 812:152124. https://doi.org/10.1016/j.jallcom.2019.152124

29. Xu XW, Pei LY, Yang Y et al (2016) Facile synthesis of $\mathrm{NiWO}_{4} /$ reduced graphene oxide nanocomposite with excellent capacitive performance for supercapacitors. J Alloy Compd 654:23-31. https://doi.org/10.1016/j.jallcom.2015.09.108

30. Lin JY, Chou SW (2013) Cathodic deposition of interlaced nanosheet-like cobalt sulfide films for high-performance supercapacitors. RSC Adv 3(6):2043-2048. https://doi.org/10.1039/ c2ra22373b

31. Ye BR, Gong C, Huang ML et al (2018) Improved performance of a CoTe//AC asymmetric supercapacitor using a redox additive aqueous electrolyte. RSC Adv 8(15):7997-8006. https://doi.org/ 10.1039/C7RA12919J

32. Ye BR, Huang ML, Fan LQ et al (2019) Co ions doped NiTe electrode material for asymmetric supercapacitor application. J Alloy Compd 776:993-1001. https://doi.org/10.1016/j.jallcom.2018.10. 358

33. Lamiel C, Nguyen VH, Tuma D et al (2016) Non-aqueous synthesis of ultrasmall $\mathrm{NiO}$ nanoparticle-intercalated graphene composite as active electrode material for supercapacitors. Mater Res Bull 83:275-283. https://doi.org/10.1016/j.materresbull.2016.06.005

34. Manikandan M, Subramani K, Sathish M et al (2020) Hydrothermal synthesis of cobalt telluride nanorods for a high performance hybrid asymmetric supercapacitor. RSC Adv 10(23):1363213641. https://doi.org/10.1039/C9RA08692G

35. Kshetri T, Singh TI, Lee YS et al (2021) Metal organic framework-derived cobalt telluride-carbon porous structured composites for high-performance supercapacitor. Compos Part B: Eng 211:108624. https://doi.org/10.1016/j.compositesb.2021.108624
36. Zhu YR, Ji XB, Wu ZP et al (2014) Spinel $\mathrm{NiCo}_{2} \mathrm{O}_{4}$ for use as a high-performance supercapacitor electrode material: understanding of its electrochemical properties. J Power Sources 267:888900. https://doi.org/10.1016/j.jpowsour.2014.05.134

37. Tian YF, Ruan YJ, Zhang JY et al (2017) Controllable growth of NiSe nanorod arrays via one-pot hydrothermal method for high areal-capacitance supercapacitors. Electrochim Acta 250:327334. https://doi.org/10.1016/j.electacta.2017.08.084

38. Lai F, Miao YE, Zuo L et al (2016) Biomass-derived nitrogendoped carbon nanofiber network: a facile template for decoration of ultrathin nickel-cobalt layered double hydroxide nanosheets as high-performance asymmetric supercapacitor electrode. Small 12(24):3235-3244 https://www.ncbi.nlm.nih.gov/pubmed/27135 $301 /$

39. Li ST, Duan YN, Teng Y et al (2019) MOF-derived tremelliform $\mathrm{Co}_{3} \mathrm{O}_{4} / \mathrm{NiO} / \mathrm{Mn}_{2} \mathrm{O}_{3}$ with excellent capacitive performance. Appl Surf Sci 478:247-254. https://doi.org/10.1016/j.apsusc.2019.01. 140

40. Zhang LL, Zhao XS (2009) Carbon-based materials as supercapacitor electrodes. Chem Soc Rev 38(9):2520-2531 https://www. ncbi.nlm.nih.gov/pubmed/19690733/

41. Gao X, Zhang HW, Guo EJ et al (2021) Hybrid two-dimensional nickel oxide-reduced graphene oxide nanosheets for supercapacitor electrodes. Microchem J 164:105979. https://doi.org/10. 1016/j.microc.2021.105979

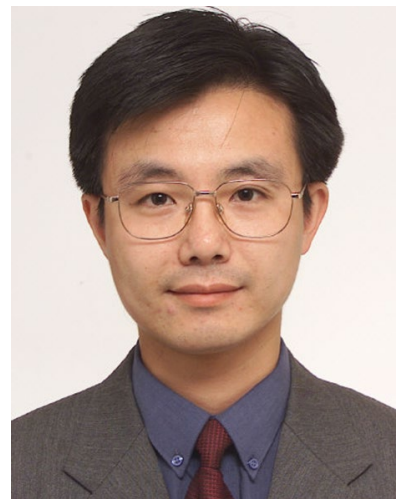

Mi Xiao received the Ph.D. degree from Tianjin University, China, in 1999, where he is currently an associate professor with the Department of Electrical Engineering, School of Electrical and Information Engineering. His research interest includes electrical insulation, synthesis and the application of electrical \& electronic functional materials. 